\title{
Changing the water paradigm: how real-time data puts sustainability into water utilities
}

\author{
G. S. Symmonds \\ Global Water FATHOM, USA
}

\begin{abstract}
Increasing hydrologic volatility means increasing risk, dramatic water supply interruption events, increased financial pressures, and potentially an imminent failure of our supply-based infrastructure. Emerging from these issues is a need to get more from our existing systems. As with transformative change in other industries, this goal will be achieved through maximizing the use of data across the entire utility ecosystem. This convergence of data will not only allow for our utilities to operate more effectively, but will be a key driver in maintaining our infrastructure, meeting our current and future demands, and assuring the revenue stability of our utilities.

Keywords: Smart Grid for Water, sustainability, utility operations, drought, demand-side management.
\end{abstract}

\section{Introduction}

For those of us who live in the southwest United States, the recent California drought declaration, the US Department of Agriculture's designation of all 15 counties in Arizona as natural-disaster areas for drought (Figure 1), and the announcement by the Bureau of Reclamation of a reduction of the discharge from Lake Powell to Lake Mead are stark reminders of the peril lurking around the corner for water utilities.

Indeed the volatility of water supply is increasing world wide - in both traditionally water scarce areas and those once considered water rich. Changes in the timing and intensity of the natural water delivery systems is demanding that we, as water professionals, reimagine what the new water delivery infrastructure and philosophy needs to be. 


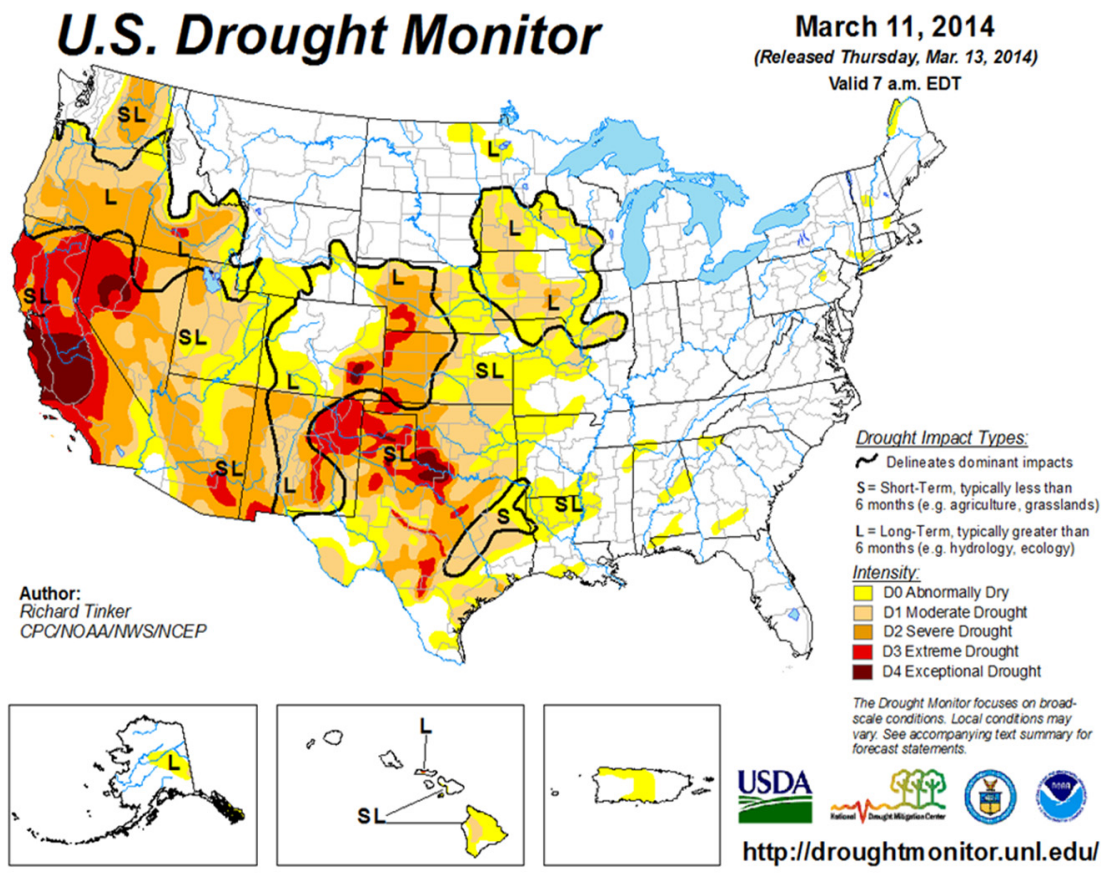

Figure 1: US drought conditions [1].

Population growth, declining availability and volatility have each conspired to reduce the real water availability per person (Figure 2 ). While the most noticeable representation of water scarcity exists in depleted lakes and rivers, municipalities and utilities have always relied on groundwater as a reserve to meet demand when water times were tough (and in some instances "excess" surface water is banked through ground storage). This reliance, however, is proving to be equally tenuous. Data from NASA's GRACE satellite has revealed that in real terms, there has been a loss of groundwater in many areas of the US - most notably in areas that have seen rapid population growth (Figure 3).

The message is clear: we cannot rely on the earth's systems to meet our water demand at the timescales we require. While the same amount of water that existed 4 billion years ago exists today, for the first time in the modern era we are approaching the limits of our engineered systems to provide a sustainable water supply. In short, water delivery variability is colliding with human activity.

The volatility of natural water delivery systems means that we must do a better job of managing our physical water resources. This means minimizing the amount of new water required and using our existing resources in the most efficient manner possible. 


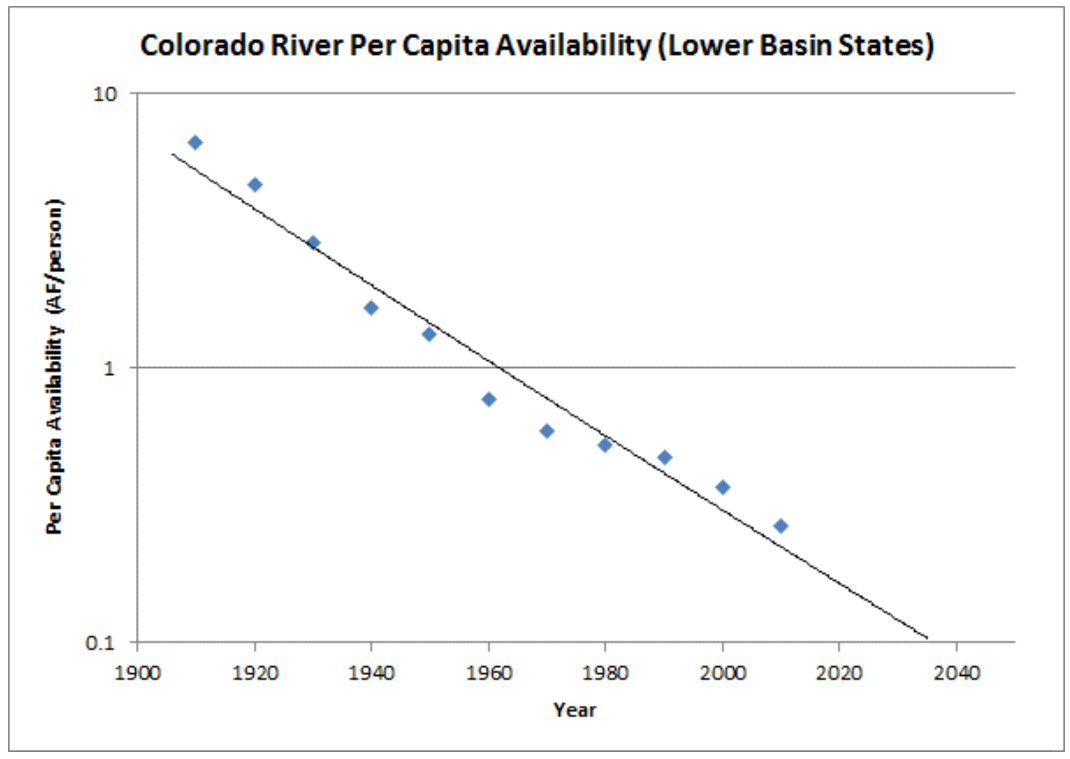

Figure 2: Declining river flows and increasing population have reduced the availability of massive rivers like the Colorado River to meet the needs of municipalities [2].

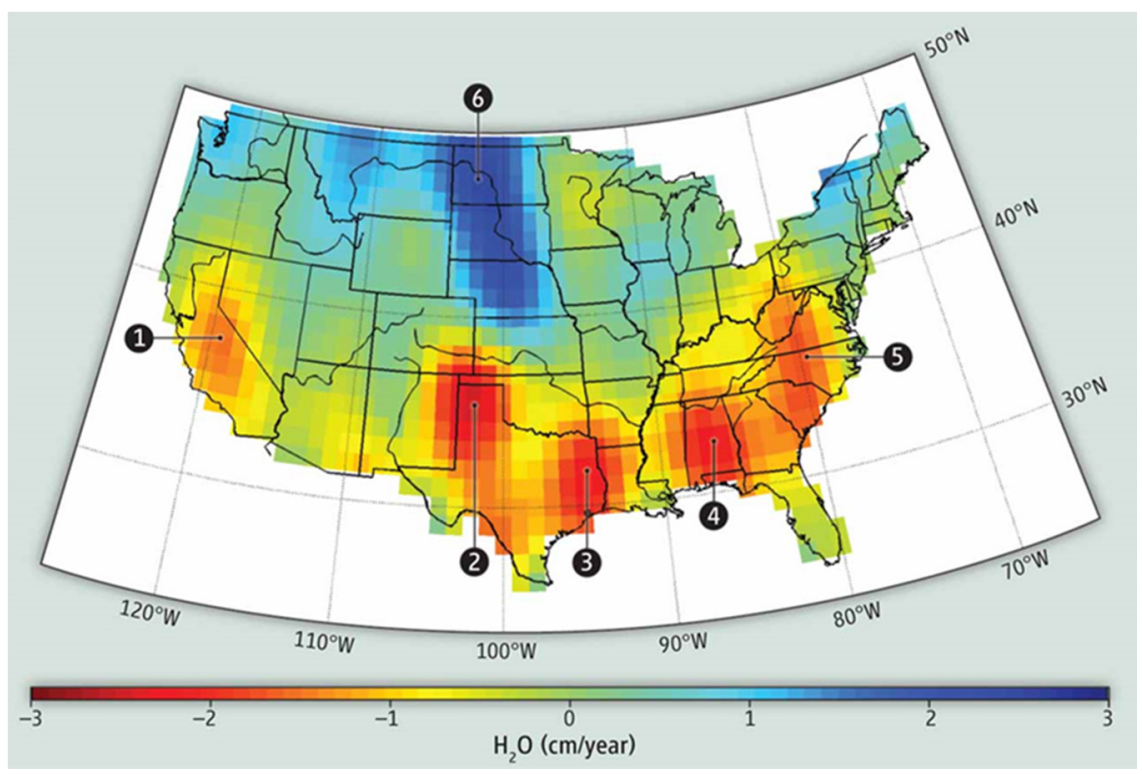

Figure 3: NASA Grace data showing continuing decline in groundwater availability [3]. 


\section{Fragmentation and financial distress}

Clearly we need to augment our supplies or invest in infrastructure and means to maintain water withdrawals at a sustainable level. There are certainly very interesting developments in the field of employing non-traditional water sources for potable water use. Indirect- and Direct-to-Potable water schemes have been or are being developed across the world - from Namibia to Texas to the International Space Station. Advances in forward osmosis and energy recovery from reverse osmosis are continuing to drive down the power consumption for production of potable water from sea and brackish sources.

The problem is that water scarcity is being played out on a stage of declining revenues in a highly fragmented industry. The EPA records more than 52,000 community water systems in operation in the United States serving over 300 million people [4]. This fragmentation has resulted in an industry that is both capital constrained and lacks economies of scale. The reason for this is obvious: water is extremely heavy and bulky to transport. This physical property of water precludes many of the benefits that electric, gas and other utilities have with dealing with resource supply and delivery efficiency. The fact remains we are not likely to connect Los Angeles to the Mississippi River any time soon.

In addition, many water utilities continue to struggle financially. A recent analysis of over 800 utilities across six states in the United States has shown that year over year, more utilities are experiencing declines in revenue (Figure 4). This means less money for capital intensive new water initiatives and increasing competition for operational dollars.

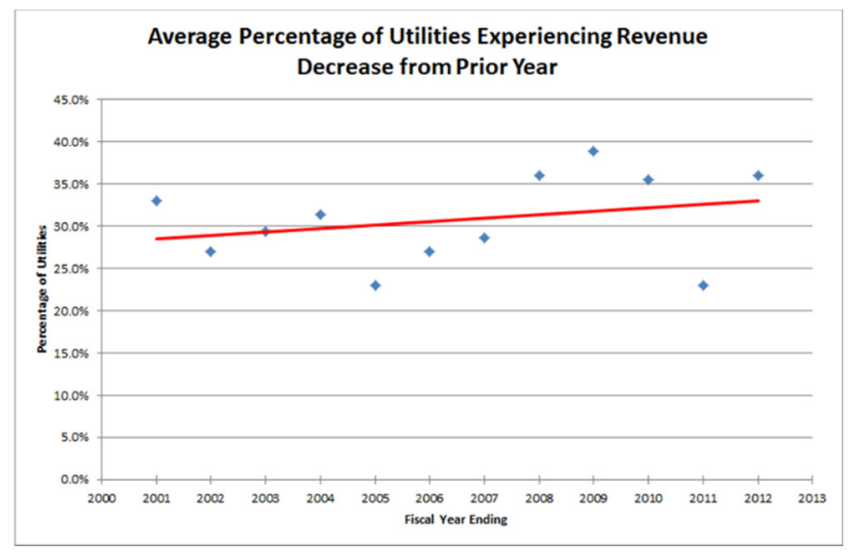

Figure 4: Increasing numbers of utilities are experiencing declining revenue [5].

\section{A new paradigm}

Clearly, the most cost effective drop of water is the one we didn't need in the first place. What that means is that utilities must be better at eliminating non-revenue water (NRW), billing for all water delivered and engaging the customer in 
meaningful and sustainable conservation. While conservation has historically been a conundrum for utilities (less water sold means less revenue), in combination with NRW reduction and data-driven financial efficiency utilities can achieve both financial and resource sustainability.

And indeed these goals can be achieved through a better understanding and use of existing systems - or investing in data systems versus heavy infrastructure. In many cases, utilities are leaking more data than water. For instance, in Qatar, the apparent losses - those losses associated with meter accuracy, billing errors, missing meters, represent twice the volume of water as do physical leaks [6].

This fact reveals that we can do much to support our water utilities by investing in data systems, and platforms that drive errors out of data or immediately notify us when data is anomalous. It also represents a singular opportunity for utilities to achieve some economies of scale in this fragmented market.

These are the fundamental tenets of the Smart Grid for Water. Employing data to become more efficient. By investing in Advanced Metering Infrastructure (AMI), utilities can turn their meters into revenue assurance devices, and ensure that both their revenue and water are highly quantified. And in doing so, in our experience utilities can find significant amounts of revenue (Figure 5) and nonrevenue water that had been hitherto hidden from view. In addition, reducing NRW means a deferral of capital expenditures on supply and distribution.

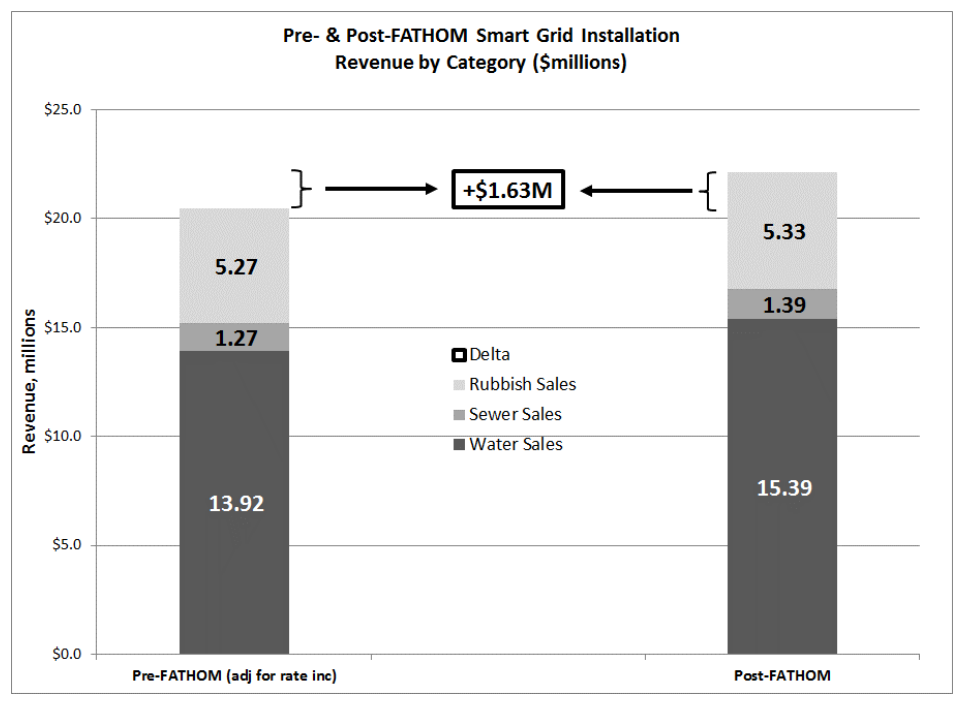

Figure 5: Improved revenue via better data management.

Not only does the Smart Grid for Water find revenue, it is also a key system for improving the financial metrics of the utility which significantly improve the utility's borrowing position. Many utilities suffer from the related problems of increasing aged receivables and bad debt. In some cases - particularly in poor economic times, or where statutory prohibition of disconnection for non-payment 
exists - utilities can see accounts become increasingly delinquent, leading ultimately to the write-off of 10 to 20 percent of billed revenue.

The adoption of data-centric smart grid technologies provides customers with a unique opportunity to correlate their actions with their water use. Prior to the availability of these tools, customers' were informed too late to make conscious and impactful decisions about their water use.

There are at the same time significant innovations being applied to rate designs to encourage behavioural adaptation by our customers. These rate designs, e.g. the Rebate Threshold Rate employed at some utilities in Arizona and water budgetbased rates increasing in popularity in California can often only be deployed in the context of increasing granularity of data - and with the necessary early warning mechanisms that provide customers with the knowledge necessary to actively manage their consumption [7].

When properly employed however, these innovative rate structures can offer significant conservation opportunities. The Rebate Threshold Rate along with advanced customer engagement has demonstrated reductions of consumption in the order of $15 \%$ and water budget based rates have shown reductions in the range of $10-15 \%$.

In concert with pricing mechanisms to encourage demand-side conservation, there is a growing understanding that people, when properly informed, can and do make conscious decisions about their water use resulting in reduction of 4 to $10 \%$.

A fundamental element in the success of these programs however, is that the messages need to be timely, meaningful and accurate. It is of little use for a customer to be told of excessive use one, two or 12 months after the fact. Utilities need to adopt a proactive communication medium with their customers: informing them of potential leaks, excessive usage, high cost and a multitude of other events. This demands granular, high frequency data.

\section{Future opportunities}

Historically, access to advanced data tools has been the provenance of the large utility. Today, however, emerging technology delivery methodologies such as cloud-based applications and software-as-a-service (SaaS) allows all scales of utilities to enjoy the data tools of their larger counterparts. Using these data-centric tools, utilities can harness the power of their data through economies of scale derived from the collective field. These techniques also eliminate distributed requirements for highly functioning IT teams, simplify deployment and maximize the availability of computing power and storage. But most importantly, these data systems form the foundation for a new relationship with our water. A relationship that maximizes the efficiency of our utilities, and the efficiency of our water use saving our most precious resource for the future.

\section{References}

[1] US Department of Agriculture, http://droughtmonitor.unl.edu/ (accessed 13 March 2014). 
[2] Global Water FATHOM, Data Sources: US Bureau of Reclamation, US Census Bureau, 2014.

[3] Famiglietti, J.S., Rodell, M., Science 2013; 340: 1300-1301, 2013.

[4] US Environmental Protection Agency, http://water.epa.gov/ infrastructure/ drinkingwater/pws/factoids.cfm (accessed 13 March 2014).

[5] Global Water FATHOM, Data Source: Environmental Finance Center at the University of North Carolina, 2014.

[6] Mattar, R., "Kahramaa's vision for non-revenue water reduction", Water Utility 21, April 2013.

[7] Hill, T.T., Symmonds, G.S. The Smart Grid for Water, Advantage Media Group, Charleston, South Carolina, 2013. 